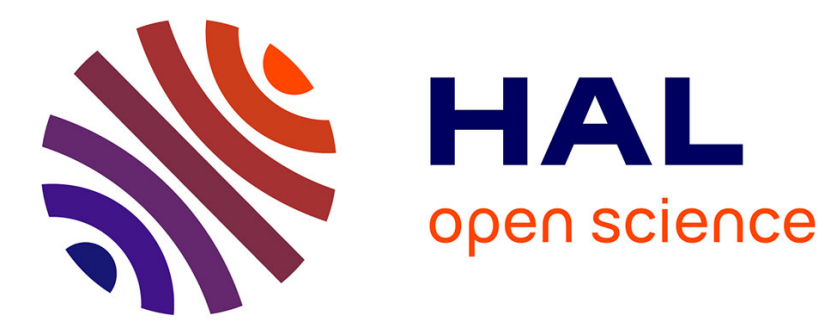

\title{
Talk, Tools, and Tensions: Observing Biological Talk Over Time
}

\author{
Justin Dillon
}

\section{To cite this version:}

Justin Dillon. Talk, Tools, and Tensions: Observing Biological Talk Over Time. International Journal of Science Education, 2007, 29 (12), pp.1581-1602. 10.1080/09500690701494118 . hal-00513355

\section{HAL Id: hal-00513355 \\ https://hal.science/hal-00513355}

Submitted on 1 Sep 2010

HAL is a multi-disciplinary open access archive for the deposit and dissemination of scientific research documents, whether they are published or not. The documents may come from teaching and research institutions in France or abroad, or from public or private research centers.
L'archive ouverte pluridisciplinaire HAL, est destinée au dépôt et à la diffusion de documents scientifiques de niveau recherche, publiés ou non, émanant des établissements d'enseignement et de recherche français ou étrangers, des laboratoires publics ou privés. 


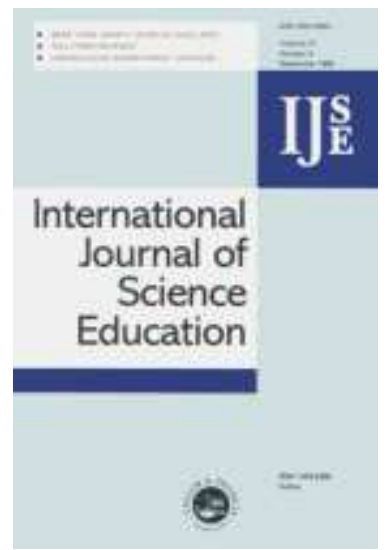

\section{Talk, Tools, and Tensions: Observing Biological Talk Over Time}

\begin{tabular}{|r|l|}
\hline Journal: & International Journal of Science Education \\
\hline Manuscript ID: & TSED-2007-0181 \\
\hline Manuscript Type: & Special Issue Research Paper \\
\hline Keywords: & informal education \\
\hline Keywords (user): & \\
\hline \multicolumn{2}{|l}{} \\
\hline
\end{tabular}

\section{scholaroNE \\ Manuscript Central}


1

2

3

4

5

6

7

8

9

10

11

12

13

14

15

16

17

18

19

20

21

22

23

24

25

26

27

28

29

30

31

32

33

34

35

36

37

38

39

40

41

42

43

44

45

46

47

48

49

50

51

52

53

54

55

56

57

58

59

60

1

Talk, Tools, and Tensions

Running Head: TALK, TOOLS AND TENSIONS

Talk, Tools, and Tensions:

Observing Biological Talk Over Time

Doris Ash, Rhiannon Crain, Carol Brandt,

Molly Loomis, Mele Wheaton and Christine Bennett

University of California Santa Cruz

Education

1156 High Street

Santa Cruz, CA 95094

Contact dash5@ucsc.edu

This work has been supported in part by NSF REC Grant \# 0133662 to Doris Ash and NSF ESI 0119787 Grant to the Center for Informal Learning and Schools (CILS) 


\begin{abstract}
The goal of this study is to explore new tools for analyzing scientific sense making in out-of-school settings. Although such measures are now common in science classroom research, dialogically-based methodological approaches are relatively new to informal learning research. Such out-of-classroom settings have more recently become a breeding ground for new design approaches for tracking scientific talk and ideas within complex data sets. The research reported here seeks to understand the language people do use to make sense of the life sciences over time. Another goal of this study is to track biological themes over time, using a new analytical scheme, Tool for Observing Biological Talk Over Time (TOBTOT). Our analyses are linked to and informed by tensions between particularistic and holistic data collection and analysis, qualitative and quantitative representations, and everyday and formal science discourse. These tensions and our analyses are linked to larger theoretical frameworks and to the recursive interplay between theory and practice.
\end{abstract}


Talk, Tools, and Tensions:

\section{Observing Biological Talk Over Time}

Research on dialogically-based scientific sense making has been central to classroom research for some time (A. Brown et al., 1993; Moje et al., 2001; Warren et al., 2001; Wells, 1999), but such research is still relatively new to outof-school settings. A growing field of scholarly research is now exploring how people talk and interact in non-classroom learning settings such as museums and aquaria (Ash, 2004; Barton, 1998; Leinhardt, Crowley \& Knutson, 2002; Paris, \& Ash, 2002). In past research, the authors have focused on the ways mixed-age, collaborative groups make sense of life science (Ash, 2002, 2004; Ash, Loomis \& Hohenstein, 2005; Crain, 2005). The research described in this paper continues this emphasis by describing a newly developed formalized tool that traces learners' use of biological themes over time (Ash, in press b). The authors' collective goal is to document, trace, and analyze biological sense making, as it happened over time, even though such moments are fleeting and seem to evaporate (Wertsch, 1998).

The Tool for Observing Biological Talk Over Time (TOBTOT) is a theoretically-informed, yet practical, system for digesting and coding large quantities of data in manageable and defensible ways, both in real time (over several hours) and across time (days, months, years). The TOBTOT was designed, tested and redesigned to quantify qualitative data, to capture both holistic and particularistic aspects of collaborative discourse, and to recognize 
multiple science discourses. The TOBTOT works in conjunction with qualitative software to organize and quantify results, which are used alongside ethnographic data, specialized interview techniques, and case study material. The TOBTOT categorizes dialogue into major biological themes and sub-themes, allowing researchers to document the ebb and flow of collaborative biological talk over the course of one or more events. Such characteristics help researchers document the social and disciplinary resources people actually do draw upon, as they talk science (Lemke, 1990).

The TOBTOT's design was grounded in a syncretic theoretical framework. Syncretism refers to merging and analyzing originally discrete traditions, asserting an underlying unity, or reconfirming an underlying discontinuity with more clarity. We argue that such syncretic approaches, when combined with constantly checking against the data, are important to the emerging discipline of research on learning in informal learning settings.

In the sections below, we first situate the development of The TOBTOT theoretically and provide an orientation to its purposes; second, describe what The TOBTOT can do as well as its limitations; and, finally, situate this research within three epistemic tensions: particularistic and holistic data collection and analysis, qualitative and quantitative representations, and everyday and formal science discourse.

Theoretical Underpinnings

Several theoretical traditions inform our methodological decisions. 
Following Vygotsky (1987), language is viewed as the pre-eminent tool for learning and teaching. Such assumptions are based on the idea that conversation is both emergent and structured (Halliday, 1975; Halliday \& Hasan, 1985; Wells, 1993, 1996). Following Bakhtin (1986) we view dialogue in terms of "multiple authorship of... all texts, written or spoken," (Wertsch, 1991, p. 49). Lemke (1998) expressed such views succinctly saying, "All language in use, whether spoken or written, is explicitly or implicitly dialogical...it is addressed to someone, and addresses them and its own thematic content, from some point-ofview" (p. 181). Such theory suggests that talking, listening, responding, gesturing, interacting with others and with the artifacts and living objects in museums and aquaria are central activities in making sense of science.

Key aspects of such research include identifying and tracking the quality and quantity of scientific subject matter content. The development of science concepts within dialogic contexts has been reported in classrooms (Kelly \& Chen, 1999; Warren et al., 2001); similar research has been less evident in informal learning settings. Classroom researchers have found it useful it to look for thematic patterns (Ash, in press b; Lemke, 1990) to understand the development of science content. Lemke (1998) has suggested that the "direct uses of scientific concepts can be directly sampled, assessed, and compared... [but] you need to be familiar with both the subject matter content of the discourse or text, and with the semantics... at the level of Halliday (1985) and Hasan (1984)" (p. 184). We are reminded that content and dialogic process need to be studied in tandem in order 
to fully understand collaborative scientific sense making. Once we accept the importance of tracing thematic content, it is necessary to explore the question of 'which counts as thematic scientific content,' the formal science language of school, the informal language of everyday settings, or a combination of both (Ash, in press b).

The 'knowing' of biological content as themes (such as reproduction, adaptation, or interdependence) is often associated with specialized language, representation, and references. Such specialized language prevails in school settings, but not necessarily in museums, homes, or in community centers. We have seen in past research that people draw on a variety of cultural, social and linguistic resources in making sense of science in social learning contexts (Ash, 2004; Gutierrez, Baquedano-Lopez, \& Tejeda, 1999). The research described in this paper has recognized science discourse in many forms. Such resources have sometimes been called everyday ${ }^{1}$ language and understandings. The TOBTOT was designed to be sensitive to multiple scientific discourses.

Beyond tracing scientific themes, dialogic analysis demands organizing data into quantifiable parts, inevitably engendering discussion about 'what counts' as a reliable part. One common method is to segment talk into its functional pieces as Initiation-Response-Evaluation (IRE) exchanges (Cazden, 2001; Mehan,

\footnotetext{
${ }^{1}$ By everyday resources, we mean the spontaneous, ordinary understandings typical of non-scientists gleaned from television, newspapers, friends, school and many other distributed sources of knowing, which enable learners to create a dialogue with exhibits, one another and with the overall setting.
} 
1978) or Initiation-Response-Follow-up (IRF) exchanges (Sinclair \& Coulthard, 1975; Wells, 1993). The data presented in this paper include multiple overlapping initiations and responses inherent to naturalistic conversation. Thus, the IRE/IRF technique did not provide a system of organization able to address our questions about the multivoiced nature of scientific meaning making.

Researchers have also organized dialogue into a complex hierarchy of speech units, including episodes, sequences, exchanges and moves (Halliday \& Hasan, 1985; Nassaji \& Wells, 2000; Wells, 1993). While these tiered segments showed promise for reliably breaking down family conversations, for the research reported here the boundaries of such units were rarely clear. The orderliness of the classroom (where such methods for breaking down talk evolved) was not present in our data.

Pragmatics and interactional sociolinguistics also offer methods for segmenting conversation by looking at what people do with language, often by deconstructing a conversation into action segments (sometimes referred to as message units) (Gumperz, 1982; Schiffrin, 1994; Scott et al, 2001). This framework cannot, however, organize data into discrete units for reliably coding conversational movement through biological themes, although it did strongly influence our designs for segmenting.

In the past, we have analyzed the 'significant events' (Ash, 2002) of science dialogue, extracting representative episodes as samples, and then subjecting them to intense ethnographic and socio-linguistic analysis. The trends 
that emerge across hours of conversation do reveal how concepts are constructed in ongoing conversation. While this type of sampling and analysis is useful, and would have skirted many of the idiosyncrasies inherent in our data, it cannot and should not be the only way people examine their corpuses of data (often critiqued as 'selective anecdotalism') (Gibbs, 2002, p. 231). The delineation of discrete conversations, or the segmenting techniques used in this study, are thus an informed synthesis of several types of conversation analysis techniques.

\section{Method}

\section{Data Collection}

Data were collected over three years with twenty Spanish-speaking and English-speaking family groups in a marine biology center in northern California. Each family included one child between the ages of four and six, one child between the ages of eight and eleven, and at least one parent. Families were recruited from a local Head Start program ${ }^{2}$. Visits ranged from twenty to eighty minutes. All conversations at the same four exhibits were video- and audiorecorded, and were transcribed in both English and Spanish. Data collection was naturalistic (Ash, 2004; Moschkovich \& Brenner, 2000); a Spanish-speaking biologist served as a bilingual mediator. Ethnographic notes augmented the data. There was no material embodiment (Wells, 2002) of activity, such as a concept

2 Head Start is a comprehensive child development program funded through the U.S. Department of Health and Human Services that assists children from birth to age 5, pregnant women, and their families. Head Start is a child-focused program with the overall goal of increasing the school readiness of young children in low-income families. 
map or diagram; rather, there was a stimulated recall (Gass \& Mackay, 2000) post-interview, during which family members reflected, on camera, on selected video clips of their just-finished visit. This method allowed researchers to 'checkin' with in-the-moment interpretations of family talk (e.g., "Did you say 'that shrimp undressed here?"” or "You stared at this tank alone for a long time; what were you thinking?"). Family members communicated on different levels and in diverse ways as they moved through exhibits as an ensemble Granott, 1998), diverging and reconfiguring regularly. These natural variations generated a broad range of talk patterns.

\section{Coding Thematic Segments}

The TOBTOT first appeared in nascent form as thematic continuities in the Communities of Learners' research classroom (Ash, 2002; A. Brown, et al., 1993). A sample of this simple code is provided in Table 1.

\section{Insert Table 1}

Codes, such as $F$ to indicate Feeding and $C$ to indicate Communication, reflected the standard biological categories present in most high school biology texts, representing basic functional, structural, and behavioural characteristics of living things. This conversation-oriented lens has now been expanded to include a wider range of possible biological themes. This new code came to be known as the TOBTOT.

The TOBTOT now includes three super-ordinate categories: Staying Alive, Characterizing, and Ecological Interdependence. Each super-ordinate category 
contains subcategories. The original classroom codes (Table 1) fit under the Staying Alive (SA) category. The SA category reflects traditional biological survival characteristics and, as a result, is more easily aligned with formal biological ideas and language than are the other super-ordinate categories: Characterizing and Ecological Interdependence. The Characterizing $(\mathrm{CH})$ category marks talk that 'places', 'labels', or 'locates' organisms. This category also includes codes that note where naming and identifying comments and questions occur (e.g., “/But.../ but I don't know what kind of animal it is. It's an animal, right?’). The Ecological Interdependence (EI) category encompasses codes for themes such as 'community', 'habitat', 'human-animal interactions', as well less traditionally 'biological' codes like 'aesthetics', which captures important moments in family visits where personal attraction to beautiful or amazing organisms drives conversation. Together, these three major categories allowed us to analyze much of the actual dialogue in informal settings. The entire TOBTOT is illustrated in Table 2.

Insert Table 2 here

The developers of the TOBTOT were well versed in the structure of the discipline of biology, and therefore were attentive to the interaction of biological themes. For example, when a family discussed the size of an organism, it was not the independent topic 'size' alone that we considered biological, rather, it was the relation of the family discussion about size to other biological concerns we found relevant. The comment, "Oh, look how small it is; it must be the baby," is very 
different from, "Oh, look how small it is; I wonder why the other fish in the tank don't eat it?". Using the TOBTOT, these two comments would be coded as reproductive talk and community talk, respectively, and each code would be embedded in a series of thematically-related codes: reproductive talk as a subset of biological talk concerned with how things Stay Alive, and community talk as a subset of Ecological Processes, which is a subset of Ecological Interdependence.

This paper presents data analyzed by a team of researchers during the developmental process of the TOBTOT. Although the research team attempted to 3 adhere to Cohen's Kappa , a traditional measure for reliability of coding interview or laboratory data to standardize coding across researchers, the data analysis process resulted in varying degrees of reliability. Fortuitously, these results provided the opportunity to explore multiple methods for coding a complex data set, and to grapple theoretically with the three tensions that are presented later in this paper.

\section{Conversational Segmenting}

Our analytic framework includes guidelines for breaking transcripts into topically-related conversational segments as well as for maintaining content, speakers, and location as much as possible. This segmenting scheme was

3 The measure of reliability used was directly exported from Callanan's collaborating psychology research laboratory. Cohen's Kappa is used to calculate the degree of agreement between coders while correcting for chance agreement. Although common in peer-reviewed educational research, uncorrected, or 'just agreement' percentages (i.e., number of agreements/ total number of coded pieces), do not take into account the part of the observed agreement that is due to chance. In psychology journals a Kappa of .7 or better is generally accepted, but a standard of .85 is highly regarded as an indication of high validity, or match between coders. 
developed out of several theoretical traditions and their associated conversational segmenting techniques already discussed in the theoretical framework. Such segments preserve the complexity of conversation by separating key shifts in ideas and focus, rather than simply breaking the conversation into utterances. Analysis/Results

Macroanalyses.

The TOBTOT allowed us to meet our goals to: analyze complex dialogic data, find ways to accurately represent such dialogic data in 'easy to see' graphic forms, to characterize and abstract biological 'content', and to compare such aspects across families, exhibits and time. The TOBTOT also generated many new research questions.

There are many different ways to use the TOBTOT; we illustrate several with the three examples follow. Figure 1 (B Family $2^{\text {nd }}$ visit frequencies of three thematic types of conversations over time) represents the detailed ebb and flow of one family's aesthetic (Ecological), feeding behavior (Staying Alive) and classifying (Characterizing) talk over a sixty-minute visit. There was a great amount of initial Aesthetic talk, which lessened over time; there was also an interesting alternating pattern between Feeding and Classifying talk.

Insert Figure 1 here

The summarized data, in Figure 1, illustrate at least two important aspects of how such families naturalistically talk about living things. The B family collectively used Characterizing and Ecological Inderdependence talk more than 
Staying Alive talk. Characterizing and Ecological Inderdependence talk are aligned with everyday ways of speaking, concerns about the identity of an unknown living thing, and, importantly, with feelings, such as fear, like, and dislike, as well as glimmers of individual and collective affect. Another feature illustrated in Figure 1 is that Staying Alive talk, when it does occur, tends to occur after the Classifying and Ecological Talk within dialogue at the same exhibit. Such trends provide 'hard' evidence for the claims of museum practitioners (as well as classroom researchers) that naming, using prior knowledge, and making personal connections must occur before the formal science can begin. Graphic representations such as Figure 1, therefore, can provide compelling evidence that people use different, yet specific, traceable and quantifiable, forms of science talk to access the 'biology' at individual or across multiple science exhibits.

The TOBTOT allowed the analysis to track ideas and utterances that might have been ignored if we had adhered to a strict form of thematic coding that focused exclusively on scientific language. The data indicate that, in actuality, ordinary Characterizing talk, such as, "What is that?" is central to furthering scientific talk. Characterizing processes such as, "What is it?" involve more than just 'naming', or matching word to object; it is often followed by talk about other fundamental properties of that object, such as its food and how it hides (Staying Alive) (Ash, in revision). Naming and classifying, then, allow people to relate to unfamiliar organisms as well as to begin to build a more detailed picture of the characteristics of organisms. This finding is in agreement with previous studies of 
learning in science centers: identification behavior is a "first level" of learning interaction (Borun, Dristas, Johnson, Peter, Wagner, \& Fadigan, 1998). The research reported here provides detailed evidence for what happens after such "first level" naming events.

The TOBTOT-generated graphic patterns also point to how a category, such as Feeding (Staying Alive), changes over time, often acting as a leitmotif during hour-long visits. In such cases, questions (for example about feeding) can permeate time and context, often acting as a central core of dialogic negotiation (Ash et al., 2005). Other such patterns (taxonomic relationships, alive vs. dead) also act as thematic continuities (Ash, 2002), appearing repetitively in dialogue (Ash, 2004, in press b).

Figure 2 (Biological talk theme frequency by exhibit) displays data collected across the four target exhibits, then categorized by frequency of major codes. Just as in Figure 1, Characterising talk $(\mathrm{CH})$ was the major code at each exhibit, followed by Ecological talk, and Staying Alive. In this case the touch tank (a water table with a range of live inter-tidal organisms) generated the most talk, with Rocky Reef (featuring a live shark) next, while the other two (Marine Snow and Elephant Seals, exhibits displaying marine science researchers methods and results) has less talk overall. Figure 2 allows researchers to compare and contrast across exhibits. Again, such results provide 'concrete' evidence for views long help by both museum and classroom teachers-live animals seem interesting and motivational for learners. 
Such findings also prompted us to investigate the special role of living things as mediational means in dialogic activity, using a syncretic activity theory and psychological essentialism framework (Ash, in revision). Differences between living and non-living mediational means in such activity contexts appear pivotal to learning interactions. We are currently investigating these findings in greater detail.

\section{Insert Figure 2}

Figure 3 compares two families, the B family and the L family (the B family has two visits represented in this figure) across Aesthetics (EI), Feeding (SA), Classifying $(\mathrm{CH})$, and several other categories. Aesthetics (EI) were the most common codes, followed by Feeding (SA). This indicates that certain trends hold true both across time (B visit one and two) and across families (B and L). Figure 3 also indicates that the same family generated different categories in two separate visits; in this case the B family changed frequency in all but the Classifying codes in their second visit dialogue.

\section{Insert Figure 3}

\section{Microanalyses.}

The development and use of the TOBTOT has also uncovered essential tensions inherent in microanalysis of the same data. To stretch the limits of our analytic tool, to expand the norms of our fields, and to negotiate important goals for our research program, we noticed areas of tension between representing holistic and particularistic aspects of dialogue, quantifying qualitative data, and 
incorporating both everyday and formal science language. Such tensions are a natural part of working at the intersection of multiple, contrasting disciplines (Lemke, 1998), as well as part of a dance between a theoretical stance and the actual configuration of naturally occurring data. Discussions of each essential tension follow in three parts.

Holistic vs. particularistic treatment of conversational data.

The task of drawing boundaries in our segmenting process proved challenging. The standard protocol included two coders dividing the same piece of transcript into segments, before thematically coding segments. All coders used a mutually-agreed-upon and highly-refined set of rules for determining the endings and beginnings of segments. Attempts by different coders to segment the same data to check for agreement still sometimes yielded mismatched results. Example 1 shows how one piece of conversation can be broken down in two equally justifiable ways. Multiple segmenting pathways acknowledge the ambiguity of achieving conversational regularity the data required; this conflicts with the simultaneous need for meeting the standard of validity for the use of Cohen's Kappa.

Insert Example 1

Representing qualitative data quantitatively.

Assigning codes to units of 'topically discrete conversations' obscures, necessarily, what was actually said, and leaves behind a more generalized level of focus. Viewing our data through this mathematical lens tends to both 
overemphasize each instance of any code by broadening the dialogue it 'belongs to', and to underemphasize the significance of each instance in its particular conversation. For example, noticing the frequencies of 'topically discrete conversations' assigned particular thematic codes in Figures 1, 2, or 3 is a very different way of understanding scientific sense making than reading the actual text of family interactions.

Everyday vs. scientific ways of talking.

The TOBTOT can help us recognize that science can occur in everyday language, as coding within the Characterising and Ecological/Aesthetic categories demonstrated. The question of what really counts as biological talk, however, remains. Scientific language has evolved in an attempt to remove the ambiguities inherent in everyday language. Thus, recognizing whether science is happening requires disambiguating the scientific meaning making in family conversations, determining whether and how something is science. Two examples illustrate this point. The first example (Example 2) is a segment of dialogue from the $\mathrm{H}$ family. It is one topically discrete segment of conversation that is clearly recognizable as scientific. The family is engaged in a conversation about the cycle of life. The TOBTOT codes this conversation as a discussion of Ecological Community and Alive or Dead. Even though the family is clearly using 'everyday' words (dead, alive, natural, fertilizer, circle), the underlying complexity of their scientific thinking is quite apparent.

Insert Example 2 
The second example (Example 3) is not so clear. A segment of dialogue from the L family, this example illustrates a typical segment of conversation. This family again uses everyday language (plants, same, bigger, black), but the underlying themes involved are not so easily recognizable as traditional science.

\section{Insert Example 3}

Segments like these are distinctively different from canonical science talk, yet it is important to recognize that the general observations these families made were predicated on scientific principles. These families live in a world dominated by cultural scripts based upon common scientific understandings. Their 'everyday' bantering is infused with normalized explanations about the world. The ideas that animals have names, belong to particular groups, have babies, need food, and are alive, are underlying assumptions that clearly guide how people see the world. They are so well-known, in fact, that it is easy to overlook the fact that they are also the basis of formal scientific thinking and discourse. Such seemingly simple statements draw on incremental assumptions about the world that align these families with the scientific community.

While looking for how 'everyday' talk is transformed into 'scientific' talk is theoretically justified, it misses much of the work that these families did during their conversations in the museum. The data revealed how families used multiple resources to talk and act in new ways, and the use of these resources were dynamic, social, and discontinuous, not linear, direct or clear. The TOBTOT was able to code discrete patterns across families, but was not yet able to illuminate 
the nuances of how families come to these insights.

Science practice values particular ways of reasoning about the world. The TOBTOT codes do not yet capture these 'ways of reasoning'. In Examples 4a \& b, the B family 'classifies' an organism, and though the coding for two segments of discourse appears the same, these segments are qualitatively different from one another. In Example 4a, the family simply sought out the name of the crab, revealing nothing about how they actually decided it is a crab. In Example 4b, the family used a very particular 'way of reasoning' about the world to arrive at a classification. They reasoned about what kinds of marine animals have hair (whales) and tried to make sense of the fish they were looking at from this framework. Both samples have the same code using the TOBTOT.

Insert Example 4a

Insert Example 4b

\section{Discussion}

The TOBTOT traces the flux of multiple biological themes in multiperson conversations in a complex learning environment. It helps answer questions such as, "What did people talk about?," "Who was talking?," “Are there thematic shifts over the course of a visit, or over multiple visits?," and "Do different exhibits inspire different kinds of talk?". It cannot reconcile the qualitative differences between formal and everyday science talk, nor can it account for what participants 'know'. The TOBTOT also raises important research questions about what is considered biological content. Such information 
should prove useful for those designing exhibits as well as museum educators and researchers.

The TOBTOT does not yet reflect a reliable mechanism for topically segmenting conversation. Carving the part from the whole was, and continues to be, one of the most technically and theoretically challenging parts of systemic analysis. Dialogue is the verbal representation of interpersonal experience and meaning making. Line-by-line or standard IRF formats do not capture the essence of the processes inherent in dialogue. At the root of our research interest is the semantic 'meaning potential' Lemke, 1995, p. 23) that utterances and groups of utterances imply in their linguistic forms and sequences. While it is not the language itself that is interesting, language serves as a marker of experience and meaning.

Agreeing on what the people are talking about is relatively simple. The difficult part of coding dialogic conversation proved to be delineating the edges of when, where, and who constituted that talking. An individual semiotic segment of conversation is definable only by the construction of boundaries that enclose the 'segment'. We did not draw our boundaries arbitrarily, but rather chose the edges according to our interests. The paradox of this justification is that such 'segments' persist (defined by the boundaries used to define them) only by interacting in the larger discursive environment within which they are embedded. Thus, each 'segment' is 'part' of something greater (Bakhtin, 1986; Lemke, 1995, 2000). The arbitrary narrowing of focus made it challenging to define the parameters and 
'nail down' the boundaries, knowing other foci were being excluded. Seeking ways to assign meaning to blocks of text independently of the whole is antithetical to sociocultural theories of discourse, yet, as researchers, we are always faced with this same dilemma. Another's whole experience can never be known; only the bits captured on video or interpreted in field notes are accessible.

Research necessarily involves abstraction away from the actual lived experience of participants. Even 'naturalistic inquiry' (Lincoln, 1985;

Moschkovich \& Brenner, 2000) necessitates a narrowing from actual experience into collected data, whether in the form of video (the camera cannot point at everything) or participant observation. There are always decisions about the degree to which one abstracts, or infers away from that actual lived experience (Ercikan \& Roth, 2006). Tensions arise with the epistemic norms associated with varying degrees of inference away from actual experience. Rather than succumbing to the seduction of simply labelling our research as either qualitative or quantitative, we have chosen to examine the conflicts that arise when negotiating the terrain between a research question and findings.

Ercikan and Roth (2006) note three dimensions in the process of data construction: data sources, interpretation model, and data. In our case, the data sources were chosen a priori to the development of our interpretation model (the TOBTOT), and included videos of interaction and stimulated recall. Data sources might also include answers to test questions or participant observations. The development of our interpretation model is a set of coding protocols, but, in other 
research, might be scoring rules, or filters for extracting relevant data. All interpretation models directly yield data. It is the interplay between the interpretation model and data that most concerns us. As our data sources are naturally occurring interactions, the process of reducing our data with the TOBTOT as an interpretation model involves a good deal of abstraction, eventually yielding numerical quantities of biological talk.

Learning researchers and museum educators find graphs to be tangible tools, both colourful and seemingly easy to interpret. Since our research is predicated on the application of theory to practice, strong interest in graphs by practitioners in the museum field are a gratifying outcome of using the TOBTOT. Yet such graphic representation also disconnects viewers from what is actually being represented in charts and graphs, because quantifying data smoothes over the complexities in the data through interpretation. The results of applying the TOBTOT to the data, as represented in charts and graphs, looks clean, easy, and very interpretable, but these results actually represent many layers of choice in the construction of such data interpretations.

By far, the greatest epistemic tension arising in the development of the TOBTOT was acknowledging and accounting for both the diverse linguistic resources people use to make sense of science and the more traditionally acknowledged and socially valued biological canon. Scientific communication and expertise often come in forms such as "All species in the phylum Echinodermata exhibit a pentameral morphology," and not, "Look mommy, it has 
five legs like the other one." Studies in science education frequently claim there is a dichotomy between 'everyday' and 'scientific' thinking and talking. Although contemporary researchers have developed many ways to contrast 'everyday', 'informal', or 'naïve' discourse against 'scientific', 'canonical' and 'experienced' discourse, these dichotomies typically privilege scientific talk.

Because science discourse is so commonly characterized as distinct from the linguistic practices of everyday life (Yore et at., 2003), researchers are often tempted to use measures of science discourse as measures of science understanding. An approach that evaluates science learning based on the presence or absence of technical scientific vocabulary would show very little about our participants' biological thinking and talking. Yet, the families in this study were making sense of science, while using everyday science language.

While this study strongly advocates for the importance of everyday talk in science learning, it does not resolve the epistemic question about the nature of scientific thought. This epistemic tension speaks directly to contemporary conversations about equity, concerning claims about 'who' science is for, 'what' it means when particular groups tend to be unsuccessful in science, and 'how' a person needs to experience science in order to learn it. If science, as a way of thinking, is qualitatively the same as so-called 'everyday' ways of thinking, then it is necessary to recognize that science is a cultural practice (Aikenhead, 1996; Brickhouse et al., 2000; Lemke, 2001; Moschkovich \& Brenner, 2000). Studies noting the continuities and points of overlap between everyday 
and scientific understandings link them continuously across settings (Ash, 2004; Warren et al., 2001). These studies position 'everyday' and 'scientific' language and thinking along a continuum, rather than as discontinuous or mutually exclusive cognitive states. Focusing on continuities between situated everyday and formal academic science assumes students have a chance to succeed in school science and to access the 'culture of power' necessary to enter science as a professional domain. Such research also reformulates ideas about what it means to learn science. Rather than seeing science learning as just a 'cognitive' task, it allows researchers to see how learning science is also a product of particular social practices and cultures, and of changing identities, values, and culturally valued ways of thinking about the world (Barton, 1998; Lemke, 1990).

Science educators sometimes ask: "Where is the science?," believing that without the typical words of science, there is no science. Given the complexity of scientific thinking, the development of the TOBTOT was approached with great care. Yet, if the TOBTOT were to assess science learning by only looking for the development of a canonical science vocabulary, the real learning of biological processes and principles in which the families were engaged would go unrecognized. The TOBTOT is a means of equalizing everyday and scientific talk by not privileging the presence of one over the other, by honouring actual words that family members used and situating them within a proto-scientific framework.

Others have already questioned the unidirectional linearity that moving from 'everyday' to 'scientific' implies. These researchers have focused on the 
ways that learners make use of resources (Calabrese-Barton, 2003; CalabreseBarton et al., 2004), identity (Brown, 2004), and hybrid language practices (Gutiérrez et al., 1997; Gutiérrez et al., 1999) to understand how learners creatively negotiate agency within the discipline of science for different purposes. They posit that all situations assume forms of 'hybridity' and argue that hybridity needs to be reframed as a resource to capitalize on, rather than as a roadblock. By looking holistically and documenting how people activate resources in both traditional and non-traditional ways, the TOBTOT begins to break down the notions of deficit that so frequently misframe and misperceive people and their cognitions of experience.

\section{Conclusion}

The TOBTOT is a powerful tool; it has helped organize quantities of data and create an overview of how people make sense of biology, while juggling the complexity of acknowledging hybridity of everyday and scientific language and understanding. These new understandings have, however, created new questions, inspiring us to design new ways to analyze our data. The TOBTOT allows us to 'see' what people talk about with greater precision than researchers have provided heretofore. While never intending for the TOBTOT to be all-encompassing, the growing mismatch between the TOBTOT and our goals has revealed the limits of our tool, considering the broad scope of our research expectations.

The explorations delineated here are part of the expected process of collecting and analyzing data. The TOBTOT is a tool for coding large amounts of 
family conversation in marine science centers. It is built to capture thematically biological talk. Work to refine and understand this tool led to several key epistemic tensions. By exploring these tensions, especially in light of what the TOBTOT does, and does not, achieve, the authors' collective efforts have been redirected, are ongoing and move in new and positive directions.

The TOBTOT, as many other analytic tools, is not the 'right way' to analyze data. We can only work to make research decision points and epistemic tensions more conscious and transparent, even when analyzing dialogic data in the blooming, buzzing world of museums and aquariums. While our research concentrates on a particular corpus of data, other researchers will benefit from these insights and from looking closely at their own epistemic tensions. If researchers are to make sense of the data they collect, and if they are to convince others that science is truly being learned in settings outside the classroom, they must contend with the strengths and weaknesses of their research methodologies, acknowledging their limits and enjoying their benefits. 
Aikenhead, G. S. (1996). Science education: Border crossing into the subculture of science. Studies in Science Education, 27, 1-52.

Ash, D. (2002). Negotiation of thematic conversations about biology. In G. Leinhardt, K. Crowley, \& K. Knutson (Eds.), Learning conversations in museums. (pp. 357-400). Mahwah, NJ: Lawrence Erlbaum Associates.

Ash, D. (2004). Reflective scientific sense-making dialogue in two languages: The science in the dialogue and the dialogue in the science. Science Education, 88, 855-884.

Ash, D. (in revision). Making sense of living things: The need for both essentialism and activity theory. To appear in Cognition and Instruction.

Ash, D. (in press a). Using video data to capture discontinuous science meaning making in nonschool settings. In R. Goldman-Segall, S. Derry, \& R. Pea (Eds.), Video research in the learning sciences. Mahwah: Erlbaum.

Ash, D. (in press b). Thematic continuities: Talking and thinking about adaptation in a socially complex classroom. To appear in Journal of Research in Science Teaching.

Ash, D., Loomis, M., \& Hohenstein, J. (2005). ¿qué come? Preguntas para la significación de conceptos científicos. (what does it eat? Questions about meaning in scientific concepts.). Sinéctica, 26, 51-64.

Ash, D., \& Wells, G. (2006). Dialogic inquiry in classroom and museum: Actions, tools and talk. In Learning in places: Lawerence Earlbaum.

Bakhtin, M. (1986). Speech genres and other essays. Austin: University of Texas Press.

Barton, A. (1998). Teaching science with homeless children: Pedagogy, representation and identity. Journal of Research in Science Teaching, 35(4), 379-394.

Barton, A. (2003). Teaching science for social justice. New York: Teachers College Press.

Borun, M., Dristas, J., Johnson, J. I., Peter, N. E., Wagner, K. F., Fadigan, K., et al. (1998). Family learning in museums: The pisec perspective. Philadelphia: PISEC/The Franklin Institute.

Brickhouse, N. W., Lowery, P., \& Schultz, K. (2000). What kind of girl does science? The construction of school science identities. Journal of Research in Science Teaching, 37(5), 441444.

Brown, A., Ash, D., Rutherford, M., Nakagawa, K., Gordon, A., \& Campione, J. (1993). Distributed expertise in the classroom. In G. Salomon (Ed.), Distributed cognitions (pp. 188-228). New York: Cambridge University Press.

Brown, B. A. (2004). Discursive identity: Assimilation into the culture of science and its implications for minority students. Journal of Research in Science Teaching, 41(8), 810-834.

Bryman, A. (1988). Quantity and quality in social research. London: Unwin Hyman.

Cazden, C. (2001). Classroom discourse: The language of teaching and learning (2nd ed.). Portsmouth: Heinemann.

Cole, M. (1996). Cultural psychology: A once and future discipline. Cambridge: Harvard University Press.

Crain, R. (2005). Enacted artifacts in two educational spaces: University of California, Santa Cruz.

Delpit, L. (1995). Other people's children: Cultural conflict in the classroom. New York: The New Press.

Ercikan, K., \& Roth, W.-M. (2006). What good is polarizing research into qualitative and quantitative? Educational Researcher, 35(5). 
Fleiss, J. L., Nee, J. C. M., \& Landis, J. R. (1979). Large sample variance of kappa in the cases of different sets of raters. Psychological Bulletin, 86(5), 974-977.

Gass, S. A., \& Mackey, A. (2000), Stimulated Recall Methodology in Second Language Research, Lawrence Erlbaum Associates, Mahwah, New Jersey.

Granott, N. (1998). Unit of analysis in transit: From the individuals knowledge to the ensemble process. Mind, Culture, and Activity, 5(1).

Grice, H. P. (1978). Further notes on logic and conversation. In P. Cole (Ed.), Syntax and semantics (Vol. 9, pp. 41-57). New York: Academic Press.

Gumperz, J. (1982). The lingustic bases of communicative competence. In D. Tannen (Ed.), Analyzing discourse: Text and talk: Georgetown University Press.

Gutierrez, K., Baquedano-Lopez, P., \& Tejeda, C. (1999). Rethinking diversity: Hybridity and hybrid language practices in the space. Mind, Culture, and Activity, 6(4), 286-303.

Gutiérrez, K., Baquedano-Lopez, P., \& Turner, M. G. (1997). Putting language back into language arts: When the radical middle meets the third space. Language Arts, 7(5), 368378.

Halliday, M. A. K. (1975). Learning how to mean. London: Arnold.

Halliday, M. A. K., \& Hasan, R. (1985). Language, context and text: Aspects of language in a social-semiotic perspective. Oxford: Oxford University Press.

Kelly, G., \& Chen, C. (1999). The sound of music: Constructing science as sociocultural practice through oral and written discourse. Journal of Research in Science Teaching, 36, 883915.

Landis, J. R., \& Koch, G. G. (1977). The measurement of observer agreement for categorical data. Biometrics, 33, 159-174.

Lee, O., \& Fradd, S. H. (1998). Science for all, including students from non-english-language backgrounds. Educational Research, 27(4), 12-21.

Leinhardt, G., Crowley, K., \& Knutson, K. (2002). Learning conversations in museums. Mahwah, NJ: Lawrence Erlbaum Associates.

Lemke, J. (1990). Talking science: Language, learning and values. Norwood, N.J: Ablex.

Lemke, J. (1995). Textual politics: Discourse and social dynamics. London: Taylor \& Francis Publishing

Lemke, J. (1998). Analysing Verbal Data: Principles, Methods, and Problems in K. Tobin \& B. Fraser, (Eds). International Handbook of Science Education. Kluwer. (pp.1175-1189).

Lemke, J. (2000). Across the scales of time: Artifacts, activities, and (pp.1175-1189). meanings in ecosocial systems. Mind, Culture, and Activity, 7(4), 273-290.

Lemke, J. (2001). Articulating communities: Sociocultural perspectives on science education. Journal of Research in Science Teaching, 38(3), 296-316.

Lincoln, Y. G., E. (1985). Naturalistic inquiry. Beverly Hills: Sage.

Mehan, H. (1978). Structuring school structure. Harvard Educational Review, 48(1), 32-64.Miles, M. B., \& Huberman, A. M. (1984). Qualitative data analysis: A sourcebook of new methods. Newbury Park, CA: Sage.

Moje, E., Collazo, T., Carrillo, R., \& Marx, R. (2001). "maestro, what is 'quality'?" Language, literacy, and discourse in project-based science. Journal of Research in Science Teaching, 38(4), 469-498. 
Moschkovich, J. N., \& Brenner, M. E. (2000). Integrating a naturalistic paradigm into research on mathematics and science cognition and learning. In A. E. Kelly \& R. A. Lesh (Eds.), Handbook of research design in mathematics and science education. Mahwah, NJ: Lawrence Earlbaum Associates.

Nassaji, H., \& Wells, G. (2000). What's the use of "triadic dialogue"? An investigation of teacherstudent interaction. Applied Linguistics, 21(3), 376-406.

Nystrand, M. (1997). Opening dialogue: Understanding the dynamics of language and learning in the english classroom. New York: Teachers College Press.

Paris, S., \& Ash, D. (2002). Reciprocal theory building inside and outside museums. Curator, 43(3), 199-210.

Rogoff, B. (1998). Cognition as a collaborative process. In D. Kuhn \& R. Siegler (Eds.), Cognition, perception and language [vol. 2, handbook of child psychology (5th ed., pp. 679-744). New York: Wiley.

Schiffrin, D. (1987). Discourse markers. In Studies in interactional sociolinguistics (Vol. 5). Cambridge: Cambridge University Press.

Scott, M., \& Thompson, G. (Eds.). (2001). Patterns of text. Philadelphia: John Benjamins Publishing Company.

Sinclair, J. M., \& Coulthard, R. M. (1975). Towards an analysis of discourse: The english used by teachers and pupils. London: Oxford University Press.

Vygotsky, L. (1987). Thinking and speach (N. Minick, Trans.). New York: Plenum Press.

Warren, B., Ballenger, C., Ogonowski, M., Rosebery, A., \& Hudicourt-Barnes, J. (2001). Rethinking diversity in learning science: The logic of everyday sense-making. Journal of Research in Science Teaching, 38(5), 529-552.

Wells, G. (1993). Reevaluating the irf sequence: A proposal for the articualtion of theories of activity and discourse for the analysis of teaching and learning in the classroom. Linguistics and Education, 5, 1-37.

Wells, G. (1996). Using the tool-kit of discourse in activity of learning and teaching. Mind, Culture \& Activity, 3(2), 74-101.

Wells, G. (1999). Dialogic inquiry: Towards a sociocultural practice and theory of education. Cambridge, U.K.; New York: Cambridge University Press.

Wells, G. (2002). Learning and teaching for understanding: The key role of collaborative knowledge building. In J. Brophy (Ed.) Social constructivist teaching: Affordances and constraints. Advances in Research on Teaching, Vol. 9. Elsevier/JAI.

Wertsch, J. V. (1991) Voices of the mind: A sociocultural approach to mediated action. Cambridge, MA: Harvard University Press.

Wertsch, J. (1998). Mind as action. New York: University Press.

Yerrick, R., \& Roth, W.-M. (Eds.). (2005). Establishing scientific discourse communities: Multiple voices of teaching and learning research. Mahwah: Lawrence Erlbaum Associates.

Yore, L. D., Bisanz, G. L., \& Hand, B., M. (2003). Examining the literacy component of science literacy: 25 years of language arts and science research. International Journal of Science Education, 25(6), 689-725. 
Talk, Tools, and Tensions

2

3

4

5

6

7

8

9

10

11

12

13

14

15

16

17

18

19

20

21

22

23

24

25

26

27

28

29

30

31

32

33

34

35

36

37

38

39

40

41

42

43

44

45

46

47

48

49

50

51

52

53

54

55

56

57

58

59

60

URL: http://mc.manuscriptcentral.com/tsed Email: editor_ijse@hotmail.co.uk 
Tables, Figures, and Examples Ash et al; IJSE 2.07

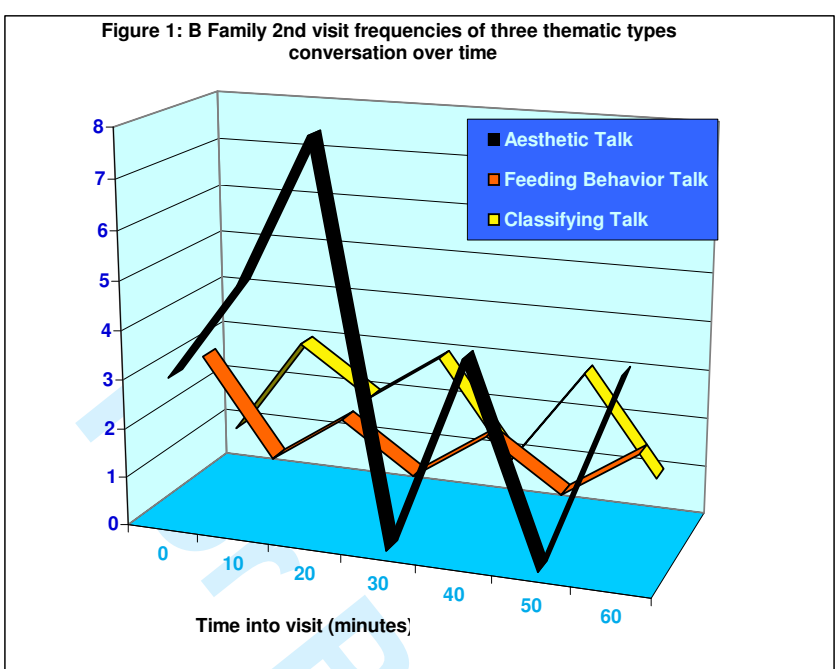

Figure 1

Figure 2

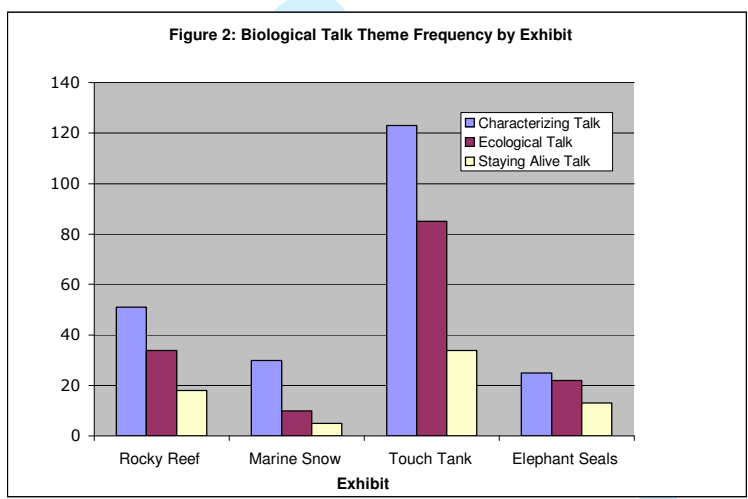

Figure 3. Three families compared

Figure 3. Codes across 3 fa,famfamilies families visits

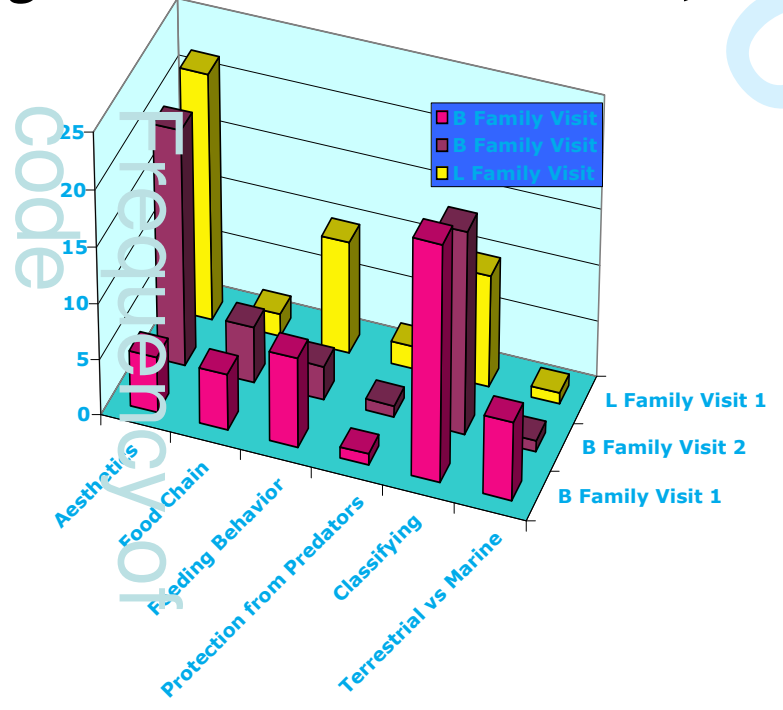


Example 1: Mis-matches in segmenting

Segmentor one's choices are in RED and segmentor two's in GREEN

1599. Yes. It's like, that's how it looks like snow.

1579. Dad: ¿Ma-? Nieve, mira. Ahorita ves, ¿okay?

1580. Ma - ? Snow, look. You can see in a minute, okay?

SEGMENT 1 START

SEGMENT 1 START

1581. Mom: (Pointing at television screen) Mira, esas... medusas.

1582. (Pointing at television screen) Look at those.... jellyfish.

1583. Dad: Oh, XXXX es nieve marina.

1584. Oh, $\mathrm{XXXX}$ it's marine snow.

1585. Mom: No, pero yo mire unas medusas.

1586. No, but I saw some jellyfish.

1587. (Your hear the audio from Mary Silver video, quite loud.)

SEGMENT 2 START

1588. Dad: Un robot, mira.

1589. A robot, look.

1590. Mediator: ¿Quieres ver más cosas? ¿Esta no te interesa? ¿Ves? Todos estos son animales XXXXX

1591. Do you want to see more things? This doesn't interest you? See? All of these are animals XXXXX

\section{SEGMENT 2 START}

1592. Dad: ¿Qué es, Paul?

1593. What is it, Paul?

1594. Son, age 11: Animales muertos.

1595. Dead animals.

1596. Dad: ¿Animales muertos?

1597. Dead animals?

1598. Mediator: Sí. Es como, se ve como nieve.
1600. Dad: Ah, hah. Pero es de animales muertos.

1601. Ah, hah. But it's from dead animals.

1602. Mediator: También hay algunos que son vivos. Pero la mayor parte son muertos.

SEGMENT 3 START

1603. There are also some that are live. But most of them are dead.

1604. Dad: Mmmm. ¿Vas a ver un libro, Son, age 7? ¿Oh, de lo que hacen en el mar abajo, verdad, m'hijo?

1605. Are you going to look at a book, Son, age 7? Oh, about what they do down below in the sea, right honey?

1606. Son, age 11: (Looking into microscope, he asks Mediator): Is that plankton?

1607. Mediator: (She leans into microscope) This is a $\mathbf{X X X}$ fish. And when it dies, it's part of a XXXXX

SEGMENT 2 END

1608. Dad: Mmmm. (Ambient noise from Mary Silver video.) (To Mom) ¿Quieres ser XXXX Mamá, para que vayas abajo del mar? ¿No?

1609. (Ambient noise from Mary Silver video.) (To Mom) Do you want to be a XXXX Mama, so you can go down in the sea? No?

1610. (Mom shakes her head 'no'.) SEGMENT 3 END

\section{Example 2: A segment easily recognized as 'scientific' Codes: 'Ecological Community', 'Alive or Dead'}

\author{
1231. Mediator: Es como una mezcla de \\ cosas muertas y cosas vivas. \\ 1232. It's like a mixture of dead \\ things and live things. \\ 1233. Mom: Oh, ¡Qué interesante! \\ 1234. Oh, how interesting! \\ 1235. Dad: Son como deshechos \\ naturales. \\ 1236. They're like natural wastes.
}

1237. Mediator: Muy bien. También hay, XXXXX

1238. Very good. There are also XXXXX

1239. Dad: Que... que no son malos para el ambiente porque es un parte -

1240. That... that aren't bad for the environment because it's part

1241. Mom: Es natural, ah, hah. 
1242. It's natural, ah, hah.

1243. Dad: ---- de lo natural, ¿verdad?

1244. ---- of what's natural, right?

1245. Mediator: Muy importante. Al contrario, son muy buenos porque es como una, un reciclaje natural...

1246. Very important. On the contrary, they are very good because it's like, like natural recycling...

1247. Dad: Oh...

1248 . Oh...

1249. Mom: Mmmm, mira...

1250. Mmmm, look...

1251. Sam: ¡Mira!

1252. Look!

1253. Dad: Mira.

1254. Look.
1255. Mom: También es como abono, quizás, ¿verdad?

1256. It's also like fertilizer, maybe, right?

1257. Mediator: $\mathrm{Mm}, \mathrm{hm}$.

1258. Mm, hm.

1259. Mom: Como tipo de abono.

1260. Like a type of fertilizer.

1261. Dad: ¿Algunos animalitos comen eso, quizás?

1262. Maybe do some little animals eat this?

1263. Mediator: Sí.

1264. Yes.

1265. Dad: ¿Sí? Me imagino porque todo es un, es un círculo, ¿verdad?

1266. Yes? I imagine it because everything is, is a circle, right?
Coding: 'Observation or Question about Behaviour', 'Classifying', 'Naming'

116. Mom: Este XXXX est bonito. (Pause in her talking.) Estas son las que parecen plantas, pero son iguales, verdad?

117. This XXXXX is pretty. (Pause in her talking.) These are the ones that look like plants, but they're the same, right?

118. John: No parecen plantas.

119. They don't look like plants.

120. (There's a huge pause of silence between John, Jr. and Mom while the Mediator-Dad-Alex interaction is going on at end of tank. Lavender joins them during this pause.)

122. Mom: XXXX (Speaking to Lavender.)

123. John, Jr.: S? Hay dos.

124. Yes? There are two.

125. Mom: ¿Dnde est el otro?
126. Where's the other one?

127. John, Jr.: No s, ese es el, este es. Este es ms grande que el otro. All est el otro. All atrs lo puedes mirar.

128. I don't know, that one is the, this one is. This one is bigger than the other one. Over there's the other one. You can see him in back.

129. Mom: Y ese negro, Qu es? Qu es este negro, John?

130. And that black thing, what is it? What is that black thing, John?

131. John, Jr.: Qu? Una piedra o algo.

132. What? A rock or something.

133. Mom: Mmmm.

134. John, Jr.: XXXX para el otro. El grande.

135. XXXX for the other one. The big one.

136. (Very long silent pause as John, Jr. is gazing into the tank.)

\section{Example 4a: A segment with codes 'Classifying' and 'Observation or Question about Structure' without complex ways of reasoning}

76 (Dad and Edgar return their gaze to the sea anemone tank.)

77 Edgar: A mi me llaman la atención.

78 They get my attention.
79 Dad: Esas están XXXXX. (He crouches down to look in the tank.)

80 These are Xxxx. (He crouches down to look in the tank.)

81 Edgar: Están, están como brillantes. (He leans down.) 
86 Dad: Eso no es cangrejo.

(He leans down.)

83 (Ambient noise)

84 Edgar: Este está bien.

Cangrejo.

85 This one is good. Crab.

87 That's not a crab.

88 Edgar: Entonces, ¿Qué es, 'ire? Ese que está allá.

89 So, what is it, look? That one that's over there.

\begin{abstract}
Example 4b: A segment with codes 'Classifying', 'Observation or Question about Structure', and 'Observation or Question about Behaviour' with complex ways of reasoning
\end{abstract}

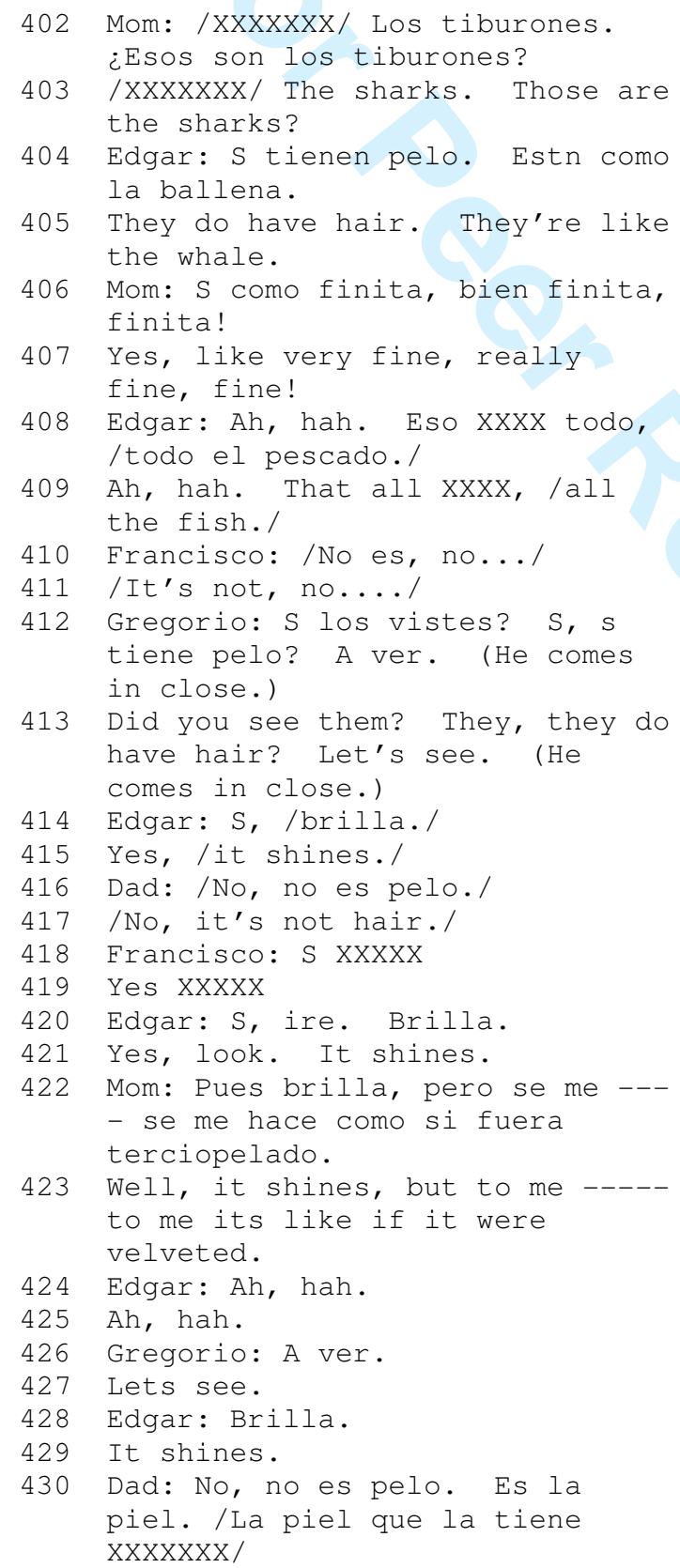

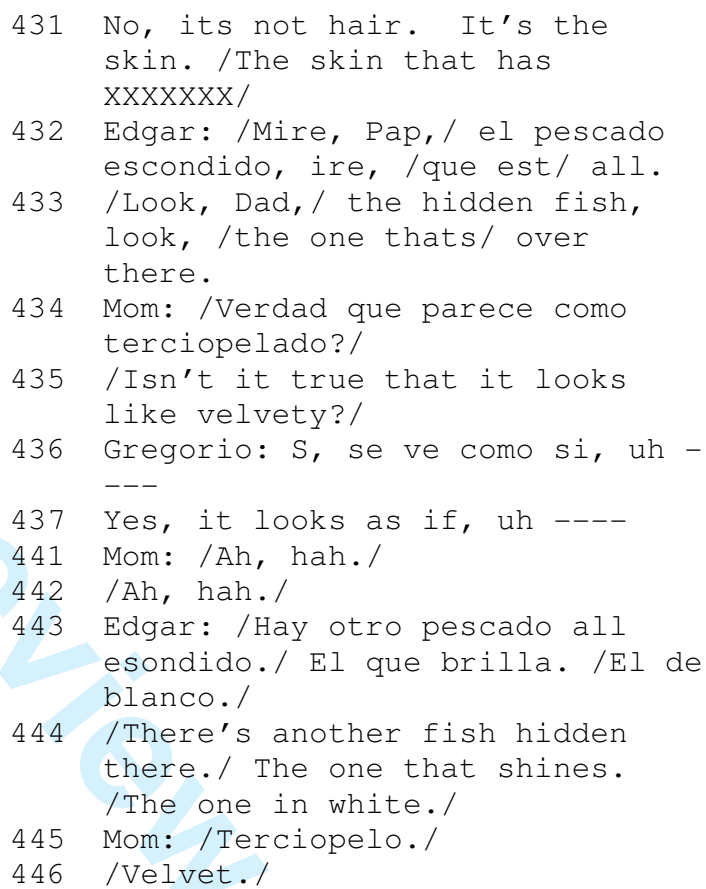

446 /Velvet./ 
1

2

3

4

5

6

7

8

9

10

11

12

13

14

15

16

17

18

19

20

21

22

23

24

25

26

27

28

29

30

31

32

33

34

35

36

37

38

39

40

41

42

43

44

45

46

47

48

49

50

51

52

53

54

55

56

57

58

59

60
Table 1. Early biological themes

Structure Function

Breeding $=\mathrm{B}$

Feeding $=\mathrm{F}$

Protection from Predators $=$ PP

Protection from Elements $=\mathrm{PE}$

Communication $=\mathrm{C}$ 
Table 2. TOBTOT Code explained

\section{Staying Alive (SA)}

When asking a question or making an observation the family or family member is trying to understand what contributes to the continuation of an animal's presence

\section{Life Cycles (LC)}

- $\quad$ Reproduction (R) - without reproduction life is pointless for an organism, as a result, much of what organisms do can be traced to their need to reproduce. A lot of noticeable structures and behaviors are related to this reproductive process.

- $\quad$ Structural Adaptations (S)

Do fish lay eggs? Anemones have lots of eggs! What are flowers for? Why does

that anemone look like its going in half?

That is the daddy, its bigger

- Behavioral Adaptations (B)

It stays with its mommy until it grows up.

Why is that fish chasing the other one? I

heard frogs can change from male to female.

- $\quad$ Growing $(\mathbf{G})$

\section{* Structural Adaptations (S)}

Those small ones will grow up to be big ones. Does it grow bigger? How much will it grow?

* Behavioral= Adaptations $(\mathbf{B})$

What does it have to do to grow bigger?

- $\quad$ Dying (D)

* Structural Adaptations (S)

It looks old, all wrinkly, like it will die

* Behavioral adaptations (B)

How long will the star fish live? Is it

dying because the shark bit it?

\section{Characteristics $(\mathbf{C H})$}

When asking a question or making an observation a family or family member is trying to figure out what something is, or how it relates to other things

\section{Placing (PI)}

- Common Name (CN)

Conversations about what organisms are called. Is this a That's a shark!

- Classification (C)

Conversations about what kind of animal they are looking at, what group does it go in? It's a mammal! That's like a hermit crab

- $\quad$ Alive vs. Dead (AD)

Don't things that are alive have a mouth? Nope, things that are alive move. Those rocks are alive? Marine snow is dead?

- $\quad$ Plant vs. Animal (PA) Are plants having mouths? That animal sure looks like a plant

- $\quad$ Terrestrial vs. Marine (TM)

Is this the same kind of snail as the ones in my backyard? Fish have to live under water. We catch frogs in the creek, but they don't live in the ocean.

- Habitat (H)

Hey, are these the same little things that live on the beach? They go "crunch" when I step on them there. These live in the rocks, right?

Observations and Questions (OQ) - often questions or comments are made that show people are noticing biology, but that don't indicate a deeper understanding of why that might be happening.

- $\quad$ Structural (S) - observations and questions that indicate a participant is noticing things and is curious about them, but that don't imply a canonical view of the phenomenon They have large mouths. Do you think that looks like an airplane too?

\section{Ecological Interdependence (EI)}

Human/Organism Relations (HOR) - Conversations sometimes include content that is specific to the relationship between organisms and humans. These types of conversations can be specific to a particular person and organism, or can more broadly be about organisms and humans in general

- Stewardship (St) - Human life interferes with the lives of other organisms on the planet

Conversations that recognize that people affect animals and plants. Does is hurt them when I step on them at the beach? Maybe that white thing in the tank is poisonous to the fish because people put it there.

People chain (PC) - People are interested in whether or not people eat something, and whether or not something is dangerous, or trying to eat them

Conversations about fishing for a certain animal, or whether or not anybody eats it. Talk about whether or not something can hurt a person or eat them. I catch those and eat them in the winter.

- $\quad$ Aesthetics (A) - Humans are drawn to "beautiful" things, and often comment on them

Comments on the beauty of a subject, on how much someone likes it, or dislikes it. Which one do you like? That is so gross!

- Cool Factor (CF) - People sometimes are drawn to a phenomenon purely because it is "cool" or neat or unknown.

"Oh wow, its so weird! Let me see!” “

Ecological Processes (EP) - Relationships between animals, plants, and their environments. Biotic and abiotic factors fundamental shape organism's lives. 
1 Energy (E) - Organisms need energy to survive - they get it in a variety of ways, the sun, plants, or other animals.

There are by-products to this process.

* Feeding (F)

- Structural Adaptations (S)

What is that aquarium woman putting into the water? Do they eat other fish? Sharks have sharp teeth to catch other animals.

* Behavioral Adaptations (B)

All the hermit crabs are climbing on each other to get to the food. The fish hides under the sand to eat? Those catch the marine snow.

* Making Food (MF)

* Structural Adaptations (S)

Why are plants green? It has leaves to get the sunlight.

* Behavioral Adaptations (B)

* Pooping (P)

* Structural Adaptations (S)

Where does it poop?

* Behavioral Adaptations (B)

It's trying to poop? Is marine snow fish poop?

\section{Protection from world (PW)}

Besides eating and reproducing, animals need to survive

threats from the outside world; they have a variety of

structures and behaviors that deal with this problem

* Predators (Pr)

- $\quad$ Structural Adaptations (S)

Discussion of physical systems of the body designed to help organisms stay safe from other organisms. Why does it look like a

rock? I bet the big one is meaner. That urchin must have spines so no one will step on it. Does that shark have spots so we won't step on it?

- Behavioral Adaptations (B)

Talking about purposes for animal behavior. Why does that fish wedge itself between two rocks? Wow that fish is fast - I bet he can get away from the sharks. Is that fish hiding to stay safe?

* Environment (En)

* $\quad$ Structural Adaptations (S)

Why are seals so chubby? How does that fish live in cold water? How do dolphins hold their breath?

\section{Behavioral Adaptations (B)}

Why do the seals lie on those rocks out of the water?
- Behviroal (B) - observations and questions that indicate a participant is noticing behaviors and is curious about them, but that doesn't imply a canonical view of the phenomenon

Do you see that animal hiding behind the rock? How funny, it keeps trying to grab my hand when I touch it!

\section{- $\quad$ Food Chain (FC)}

Conversations about the importance of one type of animal or plant to another for energy

\section{Habitat (H)}

*Physical (P) - the place an organism lives, how it interacts with its physical environment.

Discussions about different climates, and about environmental change. Is it colder at the bottom of the ocean than the top? When does upwelling happen? The baby seals are here in the spring *Organism Relationships (OR) -

Certain animals and plants live in the same places and habitats. Some even have special relationships with one another, such as mutually beneficial, parasitic, and mimicry relationships. Why does the marine snow live in Monterey Bay? How come every thing in this tank lives together? These fish get sick in the summer. 